\title{
Crisis Counseling for Trauma in Early Childhood
}

\author{
Nina Permata Sari \\ University of Lambung Mangkurat \\ ninapermatasari1980.gmail.com \\ M. Arli Rusandi \\ State University of Semarang \\ arlirusandi@students.unnes.ac.id
}

\begin{abstract}
This article provides an overview of relevant literature, including specific research findings specific to early childhood vulnerability to trauma, symptoms related to traumatic events and treatment from the point of view of counseling and guidance. It is useful to educate counselors about the impact of early childhood trauma and advocacy for appropriate assessment and treatment. Maintaining kinship relationships, security and stability is essential for dealing with or even preventing trauma in early childhood. It also suggests empathy, sincere attention and acceptance as well as encouraging relationships among stakeholders.
\end{abstract}

Keywords: Crisis counseling, trauma, early childhood.

\section{INTRODUCTION}

Children are in a high risk to be exposed to traumatic events and they are also very vulnerable for several reasons such as, They are too dependent on the caregiver/nanny and do not have adequate coping skills. In addition, children also experience rapid development and growth, especially this result inmakes them to be easily affected to traumatic events.

In contrast to the body or physic that is easier to be healed through medical treatment or traditional medicine,trauma on the soul of the children can't be seen by the invisible even tends to be an abstract form base on phenomenon created by behavior of children who face trauma.

Wright (2003) states that trauma is unlike phobia that can be avoided because people who experience trauma always live with their past experiences. If a person experiences phobia against a snake, then he simply avoids to meet, see or touch the animal. But in traumatized people, although the event is not re-experienced (seen and heard), sometimes the subconscious mind command resurrects those events which have implications for sudden horror.

For children who witness the incidents of violence within the family can also experience trauma in the form of physical, mental and emotional disturbances. The experience of seeing domestic violence in children can cause problems both short and long term. In am short term such as threats to the safety of children's lives, destructive family structure, the emergence of various mental disorders. While in the long run, the potential for children to engage in violent behavior and harassment in the future, both as perpetrators and victims.
Condition of trauma usually starts from a state of deep and continuing crisis that cannot be overcome by the individuals who experience it. According to (Terr, 1994 in

Yeager Robert, 2000), there are two types of trauma in children. Type I refers to victims who experience and suffer a single traumatic event. Type II trauma refers to victims who suffered multiple traumatic events, such as ongoing and repeated incest, child abuse, or family violence; Exceptions are a single terrible traumatic event characterized by multiple murders and include inhuman scenes (e.g, body cuts), piercing, and strong scent (e.g fire and smoke).

When children confronted with extraordinary situations, such as calamities, children in this age range often feel helpless and experience intense fear and insecurity because of their inability to protect themselves. Many children don't have verbal skills and conceptual skills needed to deal effectively with sudden stress. Reactions from parents and their families often greatly affect them. Abandonment is of great concern to preschoolers, and children who lose toys, pets, or family members will need extra comfort.

\section{DISCUSSION}

More than half of children experiencing severe stress are particularly vulnerable to accidents, physical trauma, abuse and neglect, and also exposure to domestic violence or community (National Child Traumatic Stress Network, 2010). Children from birth to 5 years are particularly vulnerable to the adverse effects of trauma due to the growth of rapid development, dependence on a caregiver / nanny and limited coping skills. Nevertheless, despite decades of statistical data, counselors generally have limited knowledge 
Jackson, Hulbert, \& McGorry, 2008; Morgan \& Fisher, 2007). compared to older children and adolescents (De Young, Kenardy, \& Cobham, 2011).

A strong barrier to mobilizing trauma resources for young children is a false but preserved assumption among practitioners and the wider community that young children are not affected by trauma and misery (National Research Council and Institute of Medicine, 2000). Kaplow, Saxe, Putnam, Pynoos, \& Lieberman (2006) in their case study reported a girl who witnessed the murder of his mother by his father at the age of 19 months and seem that she did not remember the incident, until the age of 11 , she began to show severe posttraumatic symptoms .

The traumatic experience in childhood has a long-term effect on the child's feelings toward the world and their behavior. Events that remind the original trauma can cause acute traumatic reactions and post-traumatic symptoms. Caregiver often believes that the child is too young to remember the trauma and therefore it may not draw the link between child behavior and traumatic reminders.

\section{Trauma Symptoms in Early Childhood}

Buss, Warren, \& Horton (2015) in their literature review concluded that trauma reactions can manifest in various ways in children with child-to-child variantce. In addition, children often experience trauma again. Furthermore, children exposed to traumatic events may avoid conversations, people, objects, places or situations that remind them to trauma. They often have a lack of interest to play or other activities, essentially withdrawing from interaction. Other common symptoms include hyperarousal (e.g, tantrum anger), increased irritability, insomnia, constant vigilance, concentration difficulty, excessive shock, increased physical aggression and increased activity levels. Child trauma can show changes in eating and sleeping patterns, becomes easy frustration easily, increases separation anxiety, or develops an inability to regulate urine or encopresis, it is resulting loss of acquiring developmental skills. Many of the symptoms of trauma exposure can be attributed to depression, anxiety disorder, attention-deficits, hyperactive disorders, and behavioral disorders that challenge regulatory or other developmental crises.

\section{The Consequences of Long-Term Trauma of Early Childhood}

Researchers have found clear evidence that children who experience traumatic events in early childhood are affected well beyond their youth. PTSD, anxiety disorders, behavioral abnormalities and substance abuse are all associated with traumatic events experienced in early childhood (Kanel, 2015). Mental health disorders as well as alcohol and substance abuse appear with age. The changing in brain function and physical health problems are also associated with early childhood trauma. This results in disorderly behavioral patterns of behavior, attentiondeficits, behavioral disorders and substance abuse (BriggsGowan et al, 2010) that will affect academic achievement, experience psychotic symptoms and most severely lead to the development of schizophrenia in the future (Bendall,

\section{Treatment}

Early intervention and treatment can minimize the social and emotional impact of child exposure to traumatic events. Demonstrating empathy, sincere attention and acceptance also encourage relationships among stakeholders. Combining existing coping strategies can work to minimize family stress and foster relationships with children. Providing information about community support groups or other mental health agencies and resources can also help support and encourage families. Informing parents and caregiver about common symptoms for children affected by traumatic events can raise awareness and allow for adequate support during the treatment process. Counselors can help families establish or rebuild routines that begin restoring stability to children and minimizing the impact of trauma.

Counseling assistance services performed for children is expected to have a positive impact on the optimization of potential children. For that, the task of providing assistance is not an easy task. This is because performance in the counseling process has a significant impact on the individual's life.

Some Approaches are use in counseling services. According to Myrick (in Muro \& Kottman, 1995) there are four approaches that can be formulated as an approach in guidance, namely crisis approach, remedial approach, preventive approach and developmental approach.

In the crisis approach, counseling services are conducted when a problem is found that the crisis must be addressed immediately and the teacher or counselor acts to help the child facing the problem to resolve it. The techniques used in this approach are techniques that are "definitely" able to overcome the crisis.

In the remedial approach, the teacher or counselor will focus his or her assistance on healing or corrective measures to the child's weaknesses. The purpose of assistance from this approach is to avoid possible crisis. Strategies can be used to help children, such as teaching children learning skills, social skills and the like that children do not have before.

The preventive approach is an approach that tries to anticipate problems that may arise in children and prevent the occurrence of the problem. Problems in kindergarten children can be fighting, theft, destruction, attack and so on .

The developmental approach is a more up-to-date and proactive, compared to the above three approaches. In the developmental approach, the need for guidance services in kindergarten emerges from the characteristics and problems of the students' development, both the problems deals with the physical development of motor, cognitive, social, emotional, and language. Buss, Warren, \& Horton (2015) collect from previous studies on trauma management, specifically counselors can do the treatment with the some approaches:

1. Trauma-focused cognitive behavioral therapy (TF-CBT) is a form of therapy to help children develop different perceptions and more adaptive understanding of traumatic events. 
Parents must be patient, if children are in fear and also do the parents; this leads the children in more fear. It this condition occurs because the child is following adult's behavior and style, especially parents. To overcome trauma in children requires intent and genuine cooperation from all parties, parents, teachers, and the environment both at school and at home.

Although many treatment techniques are offered, it is neccecary to notice more, according to (Laambert, (1992) in Sommers-Flanagan, 2004) that techniques are only $15 \%$ as a factor of therapeutic change in client. This does not mean that technique,, However according to lambert (Asay \& Lambert, 1999 in Sommers-Flanagan, 2004) many clients who experience spontaneous remission (sudden improvement without therapy) do so because of the positive support of important people in their lives. Lambert argues that the extratherapeutic change factor is about $40 \%$ of what causes the client to succeed in therapy. In addition, Lambert estimates that the "relationship" factor of therapy is about $30 \%$ of the variation in therapeutic outcomes.

In conclusion, maintaining family relationships, security and stability is essential to addressing or even preventing trauma in early childhood. It also suggests empathy, sincere attention, and acceptance as well as encouraging relationships among stakeholders.

\section{REFERENCES} of treatment, provide triage to identify appropriate pathways for intervention and assign referrals to community resources if necessary.

In kindergarten/early childhood program (PAUD) guidance and counseling only limited to help and directing the process of growing children to be more focused and integrated. Where the main objectives of early childhood education are: (a) training children's adaptation skills from the beginning, (B) improving verbal communication skills, (C) introducing children to the environment of the world around, such as people, things, plants, and animals, (D) providing the basics of subsequent learning, such as remembering, reading, writing and simple counting and five aspects of development stipulated in National Education Regulation (Permendiknas) No. 58 of 2009 (special orientation). Therefore, the guidanance and counseling are not only designed for children but also for parents. The integrated co-operation between parents and counselors in this case the teacher is significant so that what the goal can be achieved optimally.

\section{CONCLUSION}

Toddlers and preschool children have a high risk for trauma exposure but underrepresented in early childhood trauma research literature as well as in the development and implementation of effective clinical care. However, it should be appreciated because a small number of researchers and clinicians dedicate their time to work in this area. So the suggestions for the next researcher is be to developa comprehensive and standardized assessment instrument for early childhood.

Early childhood trauma can be overcome, the earlier age prevented, the better, the result will be considering on detrimental effect. The sense of trauma will be lost if the things children love most are highlighted (like playing).
Bendall, S., Jackson, H. J., Hulbert, C. A., \& McGorry, P. D. (2008). Childhood trauma and psychotic disorders: A systematic, critical review of the evidence. Schizophrenia Bulletin, 34, 568-579.

Briggs-Gowan, M. J., Carter, A. S., Clark, R., Augustyn, M., McCarthy, K. J., \& Ford, J. D. (2010). Exposure to potentially traumatic events in early childhood: Differential links to emergent psychopathology. Journal of Child Psychology and Psychiatry, 51, 1132-1140.

Buss, K. E., Warren, J. M., \& Horton, E. 2015. "Trauma and treatment in early childhood: A review of the historical and emerging literature for counselors". The Professional Counselor. 5(2): 225-237.

De Young, A. C., Kenardy, J. A., \& Cobham, V. E. (2011). Trauma in early childhood: A neglected population. Clinical Child \& Family Psychology Review, 14, 231-250. doi:10.1007/s10567-011-0094-3

Kanel, K. (2015). A guide to crisis intervention (5th ed.). Belmont, CA: Brooks/Cole.

Kaplow, J. B., Saxe, G. N., Putnam, F. W., Pynoos, R. S., \& Lieberman, A. F. 2006. "The Long-Term Consequences of Early Childhood Trauma: A Case Study and Discussion". Psychiatry: Interpersonal and Biological Processes, 69(4): 362-375.

Morgan, C., \& Fisher, H. (2007). Environmental factors in schizophrenia: Childhood trauma-a critical review. Schizophrenia Bulletin, 33, 3-10.

Muro, J., \& Kottman, T. 1995.Guidance and counseling in the elementary and middle schools. Dubuque. LA: Brown \& Benchmark.

National Child Traumatic Stress Network. (2010). Early childhood trauma. Retrieved from http://www.nctsn.org/sites/default/files/assets/pdfs/nctsn_ea rlychildhoodtrauma_08-2010final.pdf

National Research Council and Institute of Medicine. (2000). From neurons to neighborhoods: The science of early childhood development (pp. 267-296). Washington, DC: National Academy Press 
Sawyer, C., Peters, M. L., \& Willis, J. 2013. "Self-Efficacy of Beginning Counselors to Counsel Clients in Crisis". Journal of Counselor Preparation and Supervision. 5(2): 30-43.

Sawyer, C., Peters, M. L., \& Willis, J. 2013. "Self-Efficacy of Beginning Counselors to Counsel Clients in Crisis". Journal of Counselor Preparation and Supervision. 5(2): 30-43.

Sommers-Flanagan, John \& Sommers-Flanagan, Rita. 2004. Counseling and psychotherapy theories in context and practice: Skills, strategies, and techniques. Canada: John Wiley \& Sons, Inc.

Sommers-Flanagan, John \& Sommers-Flanagan, Rita. 2004. Counseling and psychotherapy theories in context and practice: Skills, strategies, and techniques. Canada: John Wiley \& Sons, Inc.

Wright, Susan. 2003. Be Your Own Therapist: Recipes for Emotional Health. USA: Vision Books International

Yeager, K. R., \& Robert, A. R. 2000. "Differentiating Among Stress, Acute Stress Disorder, Acute Crisis Episodes, Trauma, and PTSD: Paradigm and Treatment Goals" dalam Yeager, K. R., \& Robert, A. R (Ed), Crisis intervention handbook: assessment, treatment and research, $4^{\text {th }}$ Edition. USA : Oxford University Press. Hlm. 99-127. 